\title{
RECREATING HAMLET: CREATIVITY OF VISHAL BHARDWAJ IN HAIDER
}

\author{
K. S. Shahanaaz KOWSAR (1), Sangeeta MUKHERJEE (1)* \\ Department of English, School of Social Sciences and Languages, Vellore Institute of Technology, \\ 632014 Vellore, India
}

Received 18 November 2019; accepted 21 September 2020

\begin{abstract}
William Shakespeare's plays are universal in human character, which have raised him to be the exemplar in film industry. Shakespeare's works stand to the test of time due to their intrinsic quality of life-likeness as Arthur Koestler comments that life-likeness is regarded as the supreme criterion of art. Shakespeare's works and films project the reality of human life. The universality of his works has motivated the film producers to adapt Shakespeare extensively in their films in different regions, nations and contexts. The adaptation of the literary text into filmic interface involves major creative restructuring between the original text and the filmic medium. The restructuring of the adaptation involves shift in the medium, genre, context and culture to suit the differences in area and medium. The director of a film needs to be highly creative to adapt a literary text to make a film. Vishal Bhardwaj is one such contemporary prolific film makers who have successfully adapted Shakespearean plays like Othello, Macbeth and Hamlet into Indian cinema. The research article tries to portray the creativity of a director to recreate a new film out of an existing text (filmic adaptation). The article analyses the concept of conceptual blending creativity process and bricolage in highlighting the creativity of Bhardwaj in adapting Hamlet and localizing it in Indian cinema as Haider (2014).
\end{abstract}

Keywords: bricolage, conceptual blending, convention and creation, creativity, introjection, projective empathy.

\section{Introduction}

William Shakespeare has been canonized not only in the literary realm; but also idolized in the digital media. Shakespearean plays have been appropriated/adapted into screens due to his versatile innate human qualities that are projected in his works. Shakespeare and his contributions adapted into the celluloid and digital media have ushered a new field of studies - Shakespeare Film Studies. There are different regional and national filmic adaptations of Shakespearean plays.

Shakespearean plays were brought to India by Thomas Babington Macaulay as part of English language teaching to enable the natives to learn and perform the duties delegated by the colonial rulers before the independence. But later those plays were adapted into the Parsi

${ }^{\star}$ Corresponding author. E-mail: sangeetamukherjee70@gmail.com 
theatre after making essential changes in the plot to match the cultural shift in India. The forerunners to the Indian film industry were the Parsi theatres. This tradition of adaptation and appropriation of Shakespearean plays in theatres were later disseminated into the field of Indian cinemas. The earliest Shakespearean adaptation in Indian cinema was by director Nanubhai B. Desai who collaborated with Vaghji Asharam Oza to adapt Shakespeare's play Cymbeline into film. It was a silent film titled Champraj Hado and was released in 1923. In the domain of film adaptation, the first full length film with sound and based on Shakespeare's play Hamlet was Blood for Blood (original: Khoon Ka Khoon directed by Sohrab Modi released in 1935, starring Modi, Naseem Banu, and Shamshadbai). In Indian cinema, Shakespeare's eighteen plays have been appropriated/adapted from 1923 to 2016 (Trivedi \& Chakravarti, 2019, p. 02). Andrew Dickson comments that Indian cinema has established its superiority over other film industries in the aspect of creating different versions of Shakespeare in films (Dickson, 2015, p. 181).

One of the prominent directors who have adapted the plays of Shakespeare in contemporary Indian cinema is director Bhardwaj. His trilogy rests its foot strongly on the ethnic and cultural localization of the films in respect to setting, language and culturalism. Bhardwaj's adaptations stand unique because of his creativity to flavour the Shakespearean plays with the Indian concept of Masala, thereby appealing to the local, regional and national audience. It proves that the creativity of the director/producer plays a vital role in adapting/appropriating Shakespeare's plays in film media.

Linda Hutcheon calls adaptation "a process of creation" (Hutcheon \& O'Flynn, 2013, pp. 6-8). Film production is determined by economic, industrial, social and political influences. As economic and other factors influence films, the director should use creativity to balance the ratio between artistic pleasure, facts and economic value to cater to innovating ideas with pre-existing literary texts.

Creativity is defined as "the ability to produce work that is both novel (i.e., original, unexpected) and appropriate (i.e., useful, adaptive concerning task constraints) (Sternberg \& Lubart, 1999, p. 3). Creativity is a long-interwoven process. To have creativity, few core skills are required like - imagination, prospection and originality; these lead to creativity thereby leading to an innovative product/idea. Film is a creative product. The director imagines the idea/concept of the film, then analyses its prospection to make it feasible in reality to incorporate his ideas into film, then adds a touch of innovation to the existing ideas/concepts which results in a unique film.

Haider is a filmic adaptation of Shakespeare's Hamlet by Bhardwaj which has been taken for analysis in this paper to observe the novelty and creativity of the director (Bhardwaj) in delicately entwining the regional Kashmiri context, language and culture of India with that of Shakespeare's play Hamlet.

\section{Background of Vishal Bhardwaj's Haider}

The movie is set in the backdrop of the 1995 insurgency conflict (IC) in Kashmir, India. Haider Meer, the protagonist, comes back to Srinagar, India after 15 days of his father's disappearance. Dr. Hilal Meer (Haider's Father), gets arrested by the Armed Forces (Special 
Powers) Act (AFSPA) on the ground that he had hid and treated Ikhlaq Latif (a militant terrorist) in his house. Ghazala Meer (Haider's Mother) marries Khurram Meer, her husband's brother, after her husband's disappearance. Khurram Meer is a lawyer by profession and later becomes a member of parliament by contesting the election in Kashmir. Haider Meer is contacted by Roohdar, a friend of Dr. Hilal Meer in the army detention camp (DC). Roohdaar and Dr. Hilal Meer were in the same jail and were tortured together in the detention centers. Dr. Hilal Meer had requested Roohdaar that if the latter gets released out of the jail, he should pass this message to Haider Meer, i.e. to take revenge against Khurram Meer, Haider's Meer's own uncle, who had lustful eyes on his sister-in-law (Ghazala Meer). He also says that Khurram Meer is the one who had conspired with the army and got Dr. Hilal Meer killed. Thus, Haider Meer sets out for his revenge against Khurram Meer.

\section{Review of literature}

Choudhary (2017) analyses the differences and similarities between the plot structures of Shakespeare's Hamlet and Bhardwaj's Haider due to its cultural shift in the film. Mookherjee (2016) tries to examine the difference between the original text and its adaptation in the film Haider. The researcher discusses how far the political issues are highlighted while at the same time the core plot of the original text is maintained by the director Bhardwaj. Modak and Roy (2016) project the border problems that the citizens face in Kashmir and in the meantime how Bhardwaj firmly sticks to the crux plot of Hamlet. Chakraborti (2016) analyses how Shakespeare's Hamlet is recovered with heterogeneous issues (such as insurgency, family issues) in the film of Bhardwaj's Haider. Rana (2016) tries to portray the distinction between the storyline of Hamlet and Haider, and then continues with the unrest prevailing in Kashmir and finally compares and contrasts the soliloquies of Hamlet and Haider. The researcher concludes that Hamlet's soliloquy is filled with intrinsic meanings whereas Haider's soliloquy is explicit with meanings. Yates (2016) discusses how Hamlet tries to catch the conscience of the king through the "Mousetrap" and tries to analyse the audience's response to the play "The Murder of Gonzago", staged by Hamlet. The researcher also takes the "Mousetrap" scene from Bhardwaj's film Haider for the cultural-political analysis and future of Shakespeare in the modern world.

Researchers Ayaz et al. (2015) appreciate the efficiency of successfully transforming Shakespeare's Hamlet from Denmark to Kashmir to show the audience the pain and suffering of local citizens of Kashmir during the insurgency period. Neogi (2015) concentrates on how far the twists of the play are transported to the film Haider and its level of accuracy of adaptation of Hamlet. She discusses the relevance of Hamlet in the contemporary society of India, what are the multidimensional meanings derived from the film, and finally offers her opinion that Haider is not an exact and proper adaptation of Hamlet because the director has modified the plot to suit the Indian cultural and political background of the film.

Singh (2014) in his interview with Bhardwaj quotes that Bhardwaj had commented Haider to be an extension of what he did in Maqbool (director Bhardwaj, 2003) and Omkara (director Bhardwaj, 2006), and said that he had turned the third act of Shakespeare's Hamlet to the first act in his film. He added that he wanted his film Haider to be set in Kashmir as well 
as Kashmir to become his film's Hamlet (central role). The political turmoil and 25 years of the tragedy of Kashmir made him set his film Haider in Kashmir. He wanted to project the pressure of calamity upon the middle-class families in Kashmir who are hanging between the two extremes (army and extremist). The authentic cultural richness of Kashmiri tradition comes because of the Basharat Peer's memoir, Curfewed Night (2010). He said that composing the "Bismil" song was the most difficult one because Haider Meer had to enact the murder by still retaining the poetic flavours. Ashok (2014) opines that Bhardwaj has made a brave attempt of showing the other side of the coin where he projects the border political conflict where the ordinary Kashmiris are captured and tortured under the AFSPA in DCs and in a place called MAMA-II, the torture centre situated near the banks of Dal Lake, Srinagar. Khilnani (2014) comments that Bhardwaj has kept the inspiration of Hamlet imprinted in the movie but has added few changes in the plot to suit the ethical and cultural background of India. He is well-versed in projecting the tiffs and turns of emotional turmoil between the mother and son relationship.

\section{Objective}

The research article aims to highlight the filmmaker Bhardwaj's subtle creativity in adapting Shakespeare's play Hamlet into film Haider. It also highlights the concept of creativity in the filmic adaptation of Shakespearean plays when recontextualized in Indian cinema.

\section{Methodology}

The methodology adopted for analysis of the film Haider is descriptive methodology and the theory used for analysis in this article is Koestler's conceptual blending creativity process' theory (see 1964).

\subsection{Theory of creativity process}

The etymology of the word "creativity" is derived from the Latin word "creo" which means "to create, make". Creativity is a skill which plays a pivotal role in the fields of psychology, cognition, science and other studies. It forms the basis for innovation in all walks of life. Creativity or creation is a continuous process. Wallas (2014) produced the first model of this creative process. This model had five stages of creative process. They are preparation, incubation, intimation, illumination and verification. Similar to this theory, there are numerous creative process theories.

The current article takes the theory of conceptual blending theory of creative process. A film or movie is considered to be the visual creation in the field of creativity studies.

\subsection{Conceptual blending theory of creative process}

The theory of conceptual blending was developed by Koestler, Gilles Fauconnier and Mark Turner (see Koestler, 1964). They suggest that the creative process starts from an already existing idea/text/product. The blending of two different frameworks of ideas/text/product 
results in the development of a new domain. This process of blending is termed by Koestler as "bisociation". Koestler uses

"the term 'bisociation' in order to make a distinction between the routine skills of thinking on a single 'plane', as it were, and the creative act, which as I shall try to show, always operates on more than one plane" (1964, p. 36).

\subsection{Bricolage}

Bricolage is a French word derived from the word "bricoler" which means "to tinker". Derrida discusses the term "bricolage" in his work Structure, Sign and Play in the Discourse of the Human Sciences (1997). Bricolage helps to conceive the things that already exist in a new perspective. The new creation builds upon the different resources available in the pre-existing system.

In the above theories, it is reinforced that creativity in texts, ideas, attitudes, visual arts and products starts its process from the pre-existing resources; and the processes to achieve are blending and bricolage but they unify at a point of creativity which leads to a new creative work/idea/product as a result.

\section{Analysis: introjection}

Koestler in his theory of conceptual blending process of creativity discusses the method of "introjection" (see 1964). By introjection, he means that an individual's creative/artistic product is a result of an affinity between the personal experiences, emotions and feelings of them and others with whom they come into contact in life, which has been embedded in the unconscious mind. These shared feelings, emotions and experiences blend to create a creative art/product by the individual. Speaking about introjection, Koestler says that

"throughout his life the individual keeps introjecting chunks and patterns of other people's existence into his own; he suffers and enjoys vicariously the emotions of those with whom he becomes entangled in identificatory rapports" (1964, p. 296).

Bhardwaj, the director of Haider, has introjected the plot and story of Hamlet and the Curfewed Night and blended them to suit the cultural shift of Hamlet in the Indian context (2010).

The director of the film exhibits his creative brilliance by synthesizing two different plots/ genres - Hamlet (play) and Curfewed Night (autobiographical memoir). In this movie, the storyline of Hamlet is fixed as a frame where Haider Meer's (Prince Hamlet) mother Ghazala Meer (Gertrude) marries her husband's brother, Khurram Meer (Claudius), after the disappearance of Dr. Hilal Meer (King Hamlet). Khurram Meer betrays his own brother Dr. Hilal Meer just to marry Ghazala Meer. Khurram Meer is a secret agent of the Indian Army (IA) who falsely reports to the army that his brother is a militant. He contests in the election by using the disappearance of his brother Dr. Hilal Meer; he earns the sympathy of the local citizens by pretending to be good and as one who belongs to a victim's family. Thus, using this sympathy, he becomes the Chief Minister of Kashmir. When Haider Meer comes to know this truth, he suffers from "post-traumatic stress disorder" and later sets out for avenging his father's death at the hands of his own uncle. 
Though Shakespeare's Hamlet forms the mainframe of the film Haider, Bhardwaj has also deftly introduced the IC in Kashmir during the 1990s as a backdrop source for his movie from Peer's autobiographical novel. Bhardwaj has taken the life of Peer where Peer and his middle-class family are asked to leave their house immediately because of the Jammu Kashmir Liberation Front insurgent attack on Indian fleet close to their village. Peer's father is a civil servant in a government office in Kashmir which is a branch administrated by Delhi, India. He was also betrayed by a colleague in the workplace due to which he was attacked by militants and he escaped. Peer shortly becomes a journalist and reports the war news. In the nick of time, he records the interviews of the sufferers of army occupied territories and their struggles between the IA, the Pakistan Army and the militant groups like Lashkar-eTaiba, and Jaish-e-Mohammed who have links with Taliban. The memoir ends with the two government's gestures to liberate Kashmir from the present state to freedom which is still a far-fetched dream for the citizens and natives of Kashmir.

\subsection{Projective empathy}

Koestler comments on projective empathy in his conceptual blending theory, wherein he says that the unconscious emotions and feelings of a creator is projected in the work of art that s/he creates. Koestler comments "[...] but emotions too are projected from the self into lifeless objects; [...] The tendency to project unconsciously life and feeling into inanimate bodies [...]" (1964, p. 296). Bhardwaj acknowledges this in his interview with Singh for The Indian Express about his film Haider. Bhardwaj says,

"It was the political turmoil and the 25 years of the tragedy of Kashmir that compelled me. [...]. I've set Haider in 1995 when militancy was at its peak. I wanted to observe the human tragedy that a regular middle-class family went through. What happened to the families that didn't move away? What happened to the mother who was a teacher, the father who was a doctor, the uncle who was a lawyer? [...] We know the two extremes but the tension is always in the middle - what about the people hanging between the two extremes of the rope?" (Singh, 2014).

The empathy of Bhardwaj's emotions and feelings for the innocent people of Kashmir is expressed and projected through the film (inanimate object) Haider. It can be understood that Bhardwaj filmed this aesthetic art to make the audience understand the political, psychological and physiological struggles the people in Kashmir faced during IC. Koestler in his book The Act of Creation signifies the idea of Vernon Lee on projective empathy in the art of creation which emphasises that:

"aesthetic experience as primarily derived from 'the attribution of our own moods of dynamic experience, motor ideas to shapes. We attribute to lines not only balance, direction, velocity but also thrust, strain, feeling, intention, and character"' (1964, p. 374).

\subsection{Convention and creation}

Koestler in his book The Act of Creation (1964) observes that an artist is an introjection of personal and external experiences, thus the artist adapts strategy and selective codes to create 
a new creation breaking the conventional creations. It's basic for a new creation to break and remould what is already in the present scenario. Koestler says,

"Regardless of the period at which we look every work of art betrays the prejudiced eye, governed by selective codes which led coherence to the artist's vision, and at the same time restricts the freedom. The ensemble of these codes provides the 'rules of the game', the routine aspect of his work; while his 'strategy' must be adapted to the double environment of motif and medium. The greatness of a artist rests in creating a new, personal idiom [...] an individual code which deviates from the conventional rules" (1964, p. 380).

The movie Haider is also regarded as a convention breaking movie when compared to the other movies. Bhardwaj has been widely acclaimed in Bollywood for his filmic adaptations of Shakespearean plays. Bhardwaj displays his unique creativity by relocating Shakespeare's play in contemporary India where Kashmir and its political issues play the major role. However, at the same time, he does not lose track of the original plot of the play.

Bhardwaj has not just adapted the drama of Shakespeare into film but also has taken the strategy of culture, blending of genres, and context to nail the entire film into Indian cinemas. If it is considered in terms of genre, Bhardwaj has shifted the plot of a drama to that of a film. Bhardwaj comments that the third act of the drama is shifted to the first act in the film (Singh 2014) and has restructured a lot to suit the medium of film and context. The "Mousetrap" scene in the play of "The Murder of Gonzago" is enacted and directed by Hamlet to catch the conscious of Claudius but in the film Haider, Haider sings, dances and enacts a Kashmiri folk song "Bismil" to catch the conscious of Khurram and to warn Ghazala about the killer of her ex-husband to whom she was married then.

Bhardwaj's creativity gets contoured more in Haider. He has transposed the crucial role of the protagonist Hamlet to Kashmir and its local/regional political issues. He has bestowed his prime concern for the local/regional issues of the space and settings (Kashmir) of the film rather than the major characters in the film. Bhardwaj himself states that:

"As a film maker I wanted to make Hamlet in Kashmir. In my film, in a way Kashmir becomes Hamlet [...]. Our way of looking at Kashmir has either been cosmetic - only for shooting songs - or rhetoric, where we show a man in a phiran, holding a Kalashnikov. Haider is the first film where we see Kashmir from the inside" (Singh, 2014).

Similarly, so far as the context of creation is concerned, the sub-plot of Hamlet is about the Norwegian Crown Prince Fortinbras marching towards Denmark to avenge the death of the Norwegian King Fortinbras and to claim the land that his deceased father lost; but here in the movie the sub-plot is the issue of IC Kashmir in the 1990s. Thus, the creativity of Bhardwaj lies in his skilful adaptation of Shakespeare's plays into Indian films through relocation or regionalization.

\subsection{Bricolage}

Bricolage is an art of creation by blending and constructing with the provisions that are prevalent. Any art/language/product is evolved from an already existing art/language/product. This term bricolage was also used by Claude Lévi-Strauss in his book The Savage Mind (1968, first edition in 1962). Derrida calls all the intellectual, artistic discourse and product 
as bricolage. He defines it as "the act of borrowing concepts from different sources, and redesigning them to suit one's need” (Nagarajan, 2016, p. 163).

Bhardwaj has bricolaged Shakespeare's Hamlet and Peer's memoir Curfewed Night, and IC of Kashmir in the 1990s to produce Haider. In this redesigning of the sources to suit the Indian cultural context, Bhardwaj has neglected the Western cultural impact by letting away of scenes where Ghazala Meer dies by the poisoned wine; the closet scene in Hamlet is so culturally refined in Haider that there is no physical violence which Haider puts on Ghazala Meer as in Hamlet; the sword fight between Laertes and Hamlet has been rescripted with fight by arms and lethal weapons in the graveyard; there is no dance in Hamlet but the movie Haider has four songs and two with dance and folk music accompaniment. Thus Bhardwaj bricolages the folk music, songs, Kashmiri culture and the socio-political condition of Kashmir into the plot of Hamlet which results in the Indian adaptation of Shakespeare's Hamlet as Haider.

\section{Discussion}

Bhardwaj has pioneered in filming the tragic trilogy of Shakespeare's plays. It can be seen how the creative process while recreating a creative film has gone through different phases of conceptual blending. Bhardwaj to suit the plot of Hamlet in India has taken various measures such as collaborating with the autobiographical writer Peer to localize the plot, changing the language of the characters from Hindi to Kashmiri Urdu to suit the characters in the film; the costumes and choreography in the film are completely Indianized in the filmic adaptation of the play Hamlet. As Koestler remarks that creative art is an extension of what is already present. He further elaborates "there is no abstract art. You must always start with something" (Koestler, 1964, p. 374). Similarly, Bhardwaj started with the idea of localizing Hamlet in India and he has done it successfully through the film Haider.

\section{Conclusions}

Bhardwaj comments that very few movies are made on the issues of Kashmir. Bhardwaj's creativity takes an upper hand due to the successful synthesis of two different plots and genres to make Kashmir and its issues as the central protagonist of the movie Haider.

Bhardwaj has unconsciously gone through the process of conceptual blending creative process to create Haider. Through his projective empathy, he tries to express the difficulties and sufferings of the Kashmiri people during the IC period. He has also introjected the plot of Hamlet in the movie with Peer's Curfewed Night to root the film in Kashmiri culture and localize it. Bhardwaj has broken the same stereotyped film-making based on the Indian Masala concept and paved a way for other directors to adapt, localize and recontextualize Shakespeare's plays in the Indian context to project the contemporary issues of the region. Derrida and Lévi-Strauss' theory of bricolage comes to light where all the arts, sciences, and intellectuals are bricoleurs. The creativity of Bhardwaj in Haider proves that a creative project can blend ideas/concepts, and project the experiences, feelings, and emotions of an individual or others in its new form. 


\section{References}

Ashok, G. (2014). Haider: Shakespeare in Kashmir. The Diplomat. https://thediplomat.com/2014/10/ haider-shakespeare-in-kashmir/

Ayaz, G., Ahmed, Z., \& Ammar, A. (2015). Hamlet-Haider: From Rotten Denmark to Rotten Kashmir. International Journal of English and Education, 4(3), 116-123.

Chakraborti, S. (2016). Haider in Hamletian Cloak: Shakespeare walking through the Bazaar of Wounds. Postcolonial Interventions: An Interdisciplinary Journal of Postcolonial Studies, 1(2), 153-188.

Choudhary, V. (2017). Shakespeare in Kashmir: delineation of Hamlet's dilemma. Haider, Subodh Journal of Social Science and Humanities, 1(1), 43-46.

Derrida, J. (1997). Structure, sign and play in the discourse of the human sciences. In K. M. Newton (Ed.), Twentieth-century literary theory: a reader (pp. 115-119). St. Martin's Press. https://doi.org/10.1007/978-1-349-25934-2_24

Dickson, A. (2015). Worlds elsewhere: journeys around Shakespeare's globe. Henry Holt and Company, LLC.

Hutcheon, L., \& O'Flynn, S. (2013). A theory of adaptation. Routledge. https://doi.org/10.4324/9780203095010

Khilnani, R. (2014). Movie Review: Haider is a fabulous film. India Today. https://www.indiatoday.in/ movies/reviews/story/movie-review-haider-is-a-fabulous-film-shahid-kapoor-vidshal-bhardwajshraddha-kapoor-tabu-208375-2014-10-02

Koestler, A. (1964). The act of creation. Macmillan Inc.

Lévi-Strauss, C. (1968). The savage mind. University of Chicago Press.

Modak, P., \& Roy, S. (2016). Studying Vishal Bhardwaj's Haider: A third world reading of Shakespeare's Magnum Opus. Daath Voyage: An International Journal of Interdisciplinary Studies in English, 1, 158-163.

Mookherjee, T. (2016). Absence and repetition in Vishal Bhardwaj's Haider. Cogent Arts and Humanities, 3(1). https://doi.org/10.1080/23311983.2016.1260824

Nagarajan, M. S. (2006). English literary criticism and theory: an introductory history. Orient Black Swan.

Neogi, E. (2015). Haider: to regard or not to regard as an adaptation. https://www.academia. edu/25207509/_Haider_To_Regard_or_Not_to_Regard_As_an_Adaptation

Peer, B. (2010). Curfewed night: a frontline memoir of life, love and war in Kashmir. Scribner Book Company.

Rana, S. (2016). Hamlet’s “To Be or Not To Be” and Haider's "Main rahoon ki main nahi”: An Analysis. Language in India, 16(6), 157-165.

Singh, H. (2014). "Kashmir Is the Hamlet of My Film", says Vishal Bhardwaj on Haider. The Indian Express. https://indianexpress.com/article/entertainment/bollywood/kashmir-is-the-hamlet-of-my-film/

Sternberg, R. J., \& Lubart, T. I. (1999). The concept of creativity: prospects and paradigms. In R. J. Sternberg (Eds.), Handbook of creativity (pp. 3-15). Cambridge University Press. https://doi.org/10.1017/CBO9780511807916.003

Trivedi, P., \& Chakravarti, P. (Eds.). (2019). Shakespeare and Indian Cinemas: "Local Habitations". Series: Routledge Studies in Shakespeare. Routledge. https://doi.org/10.4324/9781315670409

Wallas, G. (2014). The art of thought. Solis Press.

Yates, E. C. (2016). Hamlet's "Mousetrap" and Haider's "Bismil": A Play-Within-A-Play/Film, audience response, and cultural politics [Master's Thesis, Michigan State University]. East Lansing, Michigan, United States. https://d.lib.msu.edu/etd/3846/datastream/OBJ/view 